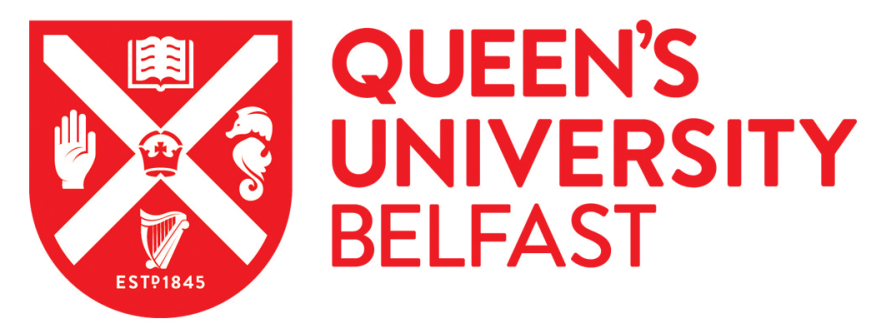

\title{
A decision support system for managing irrigation in agriculture
}

Navarro Hellin, H., Martínez-del-Rincon, J., Domingo Miguel, R., Soto Valles, F., \& Torres Sanchez, R. (2016). A decision support system for managing irrigation in agriculture. Computers and Electronics in Agriculture, 124, 121-131. https://doi.org/10.1016/j.compag.2016.04.003

\section{Published in:}

Computers and Electronics in Agriculture

\section{Document Version:}

Peer reviewed version

Queen's University Belfast - Research Portal:

Link to publication record in Queen's University Belfast Research Portal

\section{Publisher rights}

(c) 2016 Elsevier B. V. This manuscript version is made available under the CC-BY-NC-ND 4.0

licensehttp://creativecommons.org/licenses/by-nc-nd/4.0/, which permits distribution and reproduction for non-commercial purposes, provided the author and source are cited.

\section{General rights}

Copyright for the publications made accessible via the Queen's University Belfast Research Portal is retained by the author(s) and / or other copyright owners and it is a condition of accessing these publications that users recognise and abide by the legal requirements associated with these rights.

Take down policy

The Research Portal is Queen's institutional repository that provides access to Queen's research output. Every effort has been made to ensure that content in the Research Portal does not infringe any person's rights, or applicable UK laws. If you discover content in the Research Portal that you believe breaches copyright or violates any law, please contact openaccess@qub.ac.uk. 


\section{A Decision Support System for managing irrigation in}

H. Navarro-Hellín ${ }^{\mathrm{a}}$, J. Martínez-del-Rincon ${ }^{\mathrm{b}}$, R. Domingo-Miguel ${ }^{\mathrm{c}}$,

${ }^{\text {a }}$ Widhoc Smart Solutions S.L. Parque Tecnológico de Fuente Álamo, CEDIT. Carretera del Estrecho-Lobosillo Km 2 30320, Fuente Álamo. (Murcia), Spain.

${ }^{\mathrm{b}}$ The Institute of Electronics, Communications and Information Technology (ECIT), Queens University of Belfast, Belfast BT3 9DT, UK

$9 \quad{ }^{\mathrm{c}}$ Producción Vegetal Department, Universidad Politécnica de Cartagena, Paseo Alfonso XIII, 48

11 d Tecnología Electrónica Department, Universidad Politécnica de Cartagena, Campus Muralla del Mar, Doctor Fleming, s/n 30202, Cartagena (Murcia), Spain

13 e Ingeniería de Sistemas y Automática Department, Universidad Politécnica de Cartagena, Campus Muralla del Mar, Doctor Fleming, s/n 30202, Cartagena (Murcia), Spain

16 *Corresponding author at: Ingeniería de Sistemas y Automática Department, Universidad 17 Politécnica de Cartagena, Campus Muralla del Mar, Doctor Fleming, s/n 30202, Cartagena (Murcia), Spain. 


\section{Abstract}

23 In this paper, an automatic Smart Irrigation Decision Support System, SIDSS, is proposed to

24 manage irrigation in agriculture. Our system estimates the weekly irrigations needs of a 25 plantation, on the basis of both soil measurements and climatic variables gathered by several 26 autonomous nodes deployed in field. This enables a closed loop control scheme to adapt the 27 decision support system to local perturbations and estimation errors. Two machine learning 28 techniques, PLSR and ANFIS, are proposed as reasoning engine of our SIDSS. Our approach is 29 validated on three commercial plantations of citrus trees located in the South-East of Spain. 30 Performance is tested against decisions taken by a human expert.

31 Keywords: Irrigation, Decision Support System, water optimization, machine learning.

\section{Introduction}

34 The efficient use of water in agriculture is one of the most important agricultural challenges that 35 modern technologies are helping to achieve. In arid and semiarid regions, the differences between 36 precipitation and irrigation water requirements are so big that irrigation management is a priority 37 for sustainable and economically profitable crops (IDAE, 2005).

38 To accomplish this efficient use, expert agronomists rely on information from several sources 39 (soil, plant and atmosphere) to properly manage the irrigation requirements of the crops (Puerto 40 et al., 2013). This information is defined by a set of variables, which can be measured using 41 sensors, that are able to characterise the water status of the plants and the soil in order to obtain 42 their water requirements. While meteorological variables are representative of a large area and 
43 can be easily measured by a single sensor for a vast land extension, soil and plant variables have

44 a large spatial variability. Therefore, in order to use these parameters to effectively schedule the

45 irrigation of the plants, multiple sensors are needed (Naor et al., 2001).

46 Weather is one of the key factors being used to estimate the water requirements of the crops 47 (Allen et al., 1998). Moreover, it is very frequent that public agronomic management organisms 48 have weather stations spread around the different regions. These weather stations usually provide 49 information of key variables for the agriculture like reference evapotranspiration $\left(\mathrm{ET}_{0}\right)$ or the 50 Vapour Pressure Deficit (VPD) that are of great importance to calculate the water requirements 51 of the crops. Using variables related to the climate is the most common approach to create crop 52 water requirement models (Jensen et al., 1970; Smith, 2000; Zwart and Bastiaanssen, 2004). 53 Using these models, based on solely meteorological variables, a decision-making system can 54 determine how a given crop will behave (Guariso et al., 1985).

55 However, not all the regions have access to an extensive network of weather stations or they may 56 not be nearby a given crop, thus the local micro-climates are not taken into account if only these 57 parameters are used. Besides, irrigation models based only on climate parameters rely on an open 58 loop structure. This means that the model is subject to stochastic events and it may not be able to 59 correct the local perturbations that can occur when a unexpected weather phenomenon occurs (for 60 instance irrigate the crop when it's already raining) (Dutta et al., 2014; Giusti and Marsili-Libelli, 61 2015). Finally, monitoring other variables, such as hydrodynamic soil factors or water drainage, 62 might increase the chances that the irrigation predicted by the models is properly used by the 63 plants (Kramer and Boyer, 1995). Therefore, the usage of sensors that measures the soil water 64 status is a key complement to modulate the water requirements of the crops. Soil variables, such 
65 as soil moisture content or soil matric potential, are considered by many authors as crucial part of 66 scheduling tools for managing irrigation (Cardenas-Lailhacar and Dukes, 2010; Soulis et al., 67 2015). The information from soil sensors can be used to create better decision models with closed 68 loop structures that adapt to weather and soil perturbations (Cardenas-Lailhacar and Dukes, 2010; 69 Soulis et al., 2015). This practice, however, has not been widely adopted due to the technological 70 limitations of available soil sensors, which required measured information to be registered and 71 stored, traditionally using wired dataloggers, and limiting the installation flexibility and the real 72 time interaction. This has changed recently with new generation sensors and sensor networks that 73 are more versatile and suited to the agricultural environment (Navarro-Hellín et al., 2015).

74 Combining climate and soil variables has therefore potential to properly manage irrigation in a more efficient way than other traditional approaches. However, it also entails a series of 76 challenges related with the increased amount of data flow, its analysis and its use to create 77 effective models, in particular when data provided by different sources may seem contradictory 78 and/or redundant. Traditionally, this analysis and modelling is performed by a human expert who 79 interprets the different variables. The need of a human agronomist expert is required due to the 80 complexity introduced by the soil spatial variability, crop species variability and their irrigation 81 requirements over the growth cycle (Maton et al., 2005), which require comparing crops models 82 and local context variables to determine the specific water requirements to achieve a certain goal 83 at a particular location.

84 The complexity of this problem and the different sources of variability makes than even the best 85 model may deviate from the prediction, which favours the use of close loop control systems 
combining soil and climate sensors over open loop systems as a way to compensate possible deviations in future predictions.

Human expertise has been proved effective to assist irrigation management but it is not scalable and available to every field, farm and crop and it is slow in the analysis of the data and real time processing. Instead, applying machine learning techniques to replace the manual models and to assist expert agronomists allows the viability of creating automatic Irrigation Decision Support System. Machine learning techniques have been used previously to estimate relevant parameters of the crop (Sreekanth et al., 2015). Giusti and Marsili-Libelli(2015) present a fuzzy decision systems to predict the volumetric water content of the soil based on local climate data. Adeloye et al. (2012), proposed the use of unsupervised artificial neural networks (ANN) to estimate the evapotranspiration also based on weather information solely. King and Shellie (2016) used NN modelling to estimate the lower threshold temperature (Tnws) needed to calculate the crop water stress index for wine grapes. In Campos et al. (2016) the authors presented a new algorithm designed to estimate the total available water in the soil root zone of a vineyard crop, using only SWC sensors, which are very dependent of the location. Taking advantage of the soil information, Valdes-Vela et al.(2015) and Abrisqueta et al.(2015) incorporates the volumetric soil water content, manually collected with a neutron probe, to agro-meteorological data. This information is then fed into a fuzzy logic system to estimate the stem water potential. Other approaches in the literature also make use of machine learning techniques -such as principal component analysis, unsupervised clustering, ANN, etc.- to estimate the irrigation requirements in crops. However they do not specify the quantity of water needed (Dutta et al., 2014), they reduce the prediction to true or false, and/or they are based on open loop structures (Giusti and 
108 Marsili-Libelli, 2015; Jensen et al., 1970; Smith, 2000; Zwart and Bastiaanssen, 2004), only

109 considering the weather information and, therefore, unable to correct deviations from their 110 predictions.

111 This paper proposes an automated decision support system to manage the irrigation on a certain 112 crop field, based on both climatic and soil variables provided by weather stations and soil

113 sensors. As discussed, we postulate that the usage of machine learning techniques with the

114 weather and soil variables is of great importance and can help to achieve a fully automated close

115 loop system able to precisely predict the irrigation needs of a crop. Our presented system is

116 evaluated by comparing it against the irrigations reports provided by an agronomist specialist

117 during a complete season in different fields.

\section{$118 \quad 2$ System Structure}

119 An irrigation advice system is based on the concept of predicting the waters needs of the crops in

120 order to irrigate them properly. Traditionally this decision has been taken by an experienced

121 farmer or an expert agricultural technician. Figure 1 shows the flow diagram of which the 122 proposed system is based.

123 In this schema, an expert agronomist is in charge of analysing the information from different

124 sources: Weather stations located near the crops that collect meteorological data, Crop and Soil

125 characteristics (type, age, size, cycle, etc.) and Soil sensors installed in the crop fields. The expert

126 analyses the information to provide an irrigation report, which indicates the amount of water

127 needed to irrigate properly the crops in the upcoming week. To make this decision making 
128 process manageable, the information needed to create the irrigation report on the next week is 129 only the information of the current week.

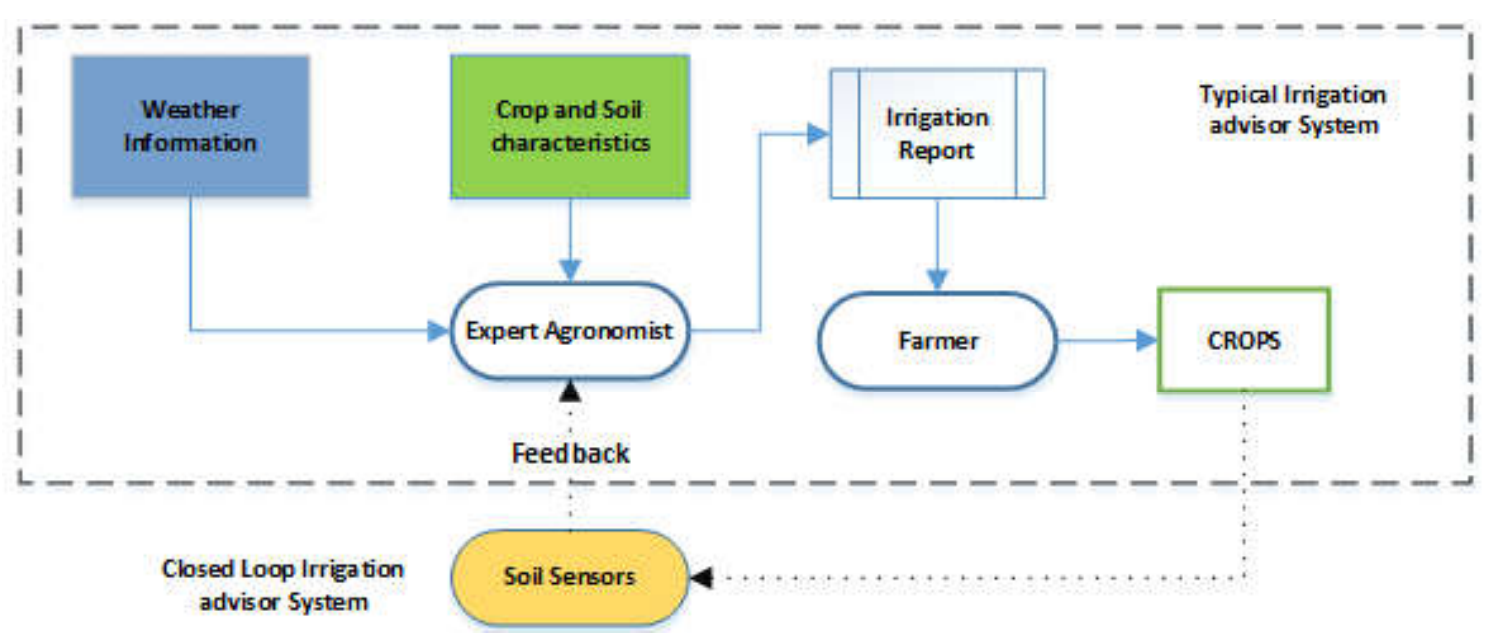

Figure 1: Flow Diagram of the proposed system

Based on this concept, our Smart Irrigation Decision Support System (SIDSS) is proposed. In order to evaluate the performance and validity of our approach, the decision system will use the same information used by the expert agronomist and will output the water requirements for the upcoming week. This will ensure a fair comparison between the decisions taken by a human expert and the SIDSS. To accomplish this, the machine learning system must be trained with historical data and irrigations reports of the agronomist, using the irrigation decisions taken in these reports as the groundtruth of the system. The aim of the system is to be as accurate as possible to this groundtruth. Several machine learning techniques were applied and evaluated to achieve the best performance. Figure 2 shows a diagram of the SIDSS.

141 The Irrigation Decision System is composed of three main components: a collection device that 142 gathers information from the soil sensors, weather stations that provide agrometeorological 143 information and the SIDSS that, when trained correctly, is able to predict the irrigation 
144 requirements of the crops for the incoming week. Table 1 shows the set of possible input 145 variables of the system.

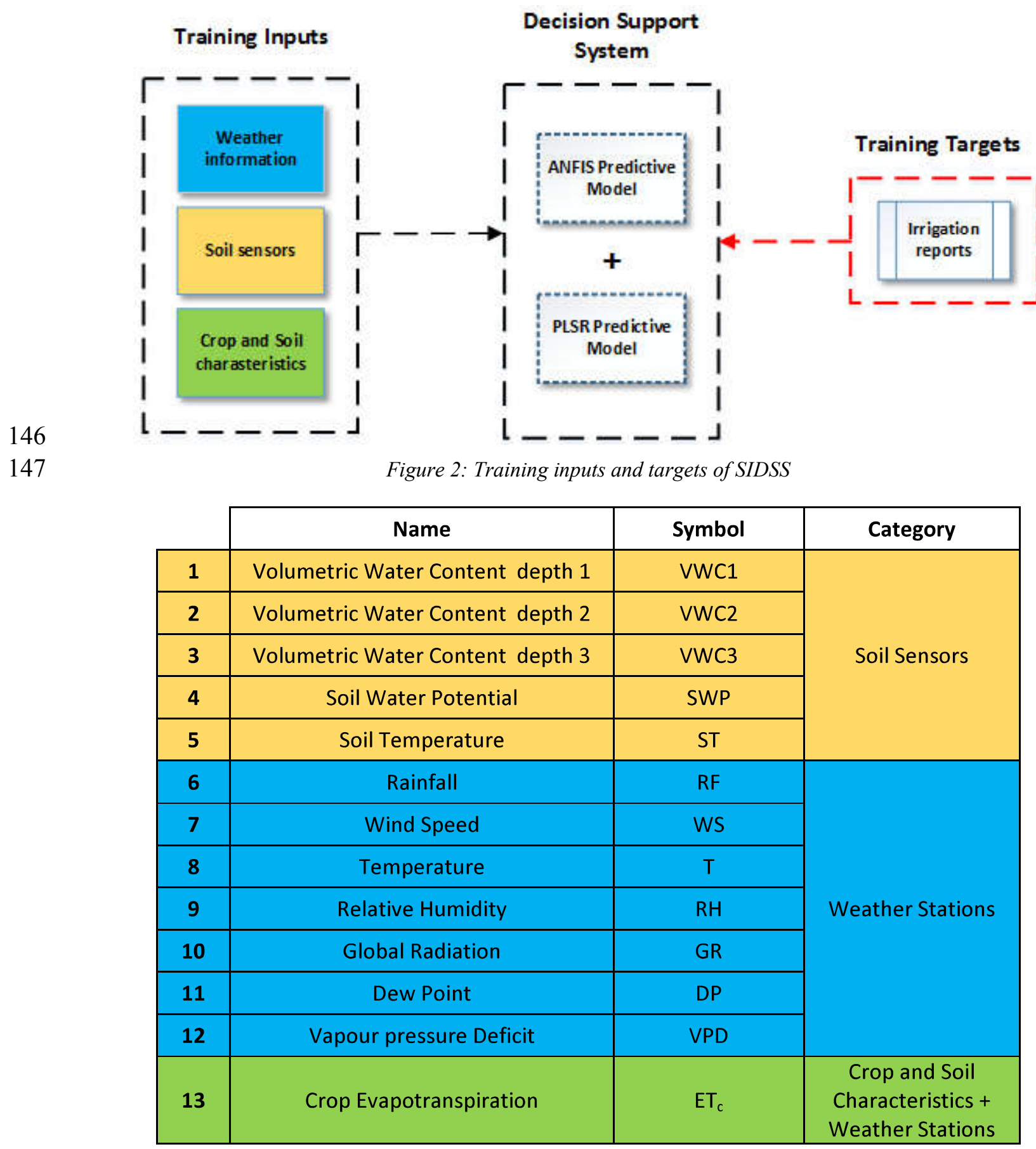




\section{$149 \quad 2.1$ Collection device and soil sensors}

150 The information from the soil sensors is gathered using our own developed device that has been

151 proved to be completely functional for irrigation management in different crops and conditions

152 (Navarro-Hellin et al., 2015). This device is wireless, equipped with a GSM/GPRS modem, and

153 is completely autonomous, so that the installation procedures are accessible to any farmer.

154 Figure 3 shows the collection device installed in a lemon crop field located in the South-East of 155 Spain.

156

158 The device allows to fully configure the recording rates of all the embedded sensors. In our 159 experiments, a sampling rate of 15 minutes was set, since this gives a good balance between 160

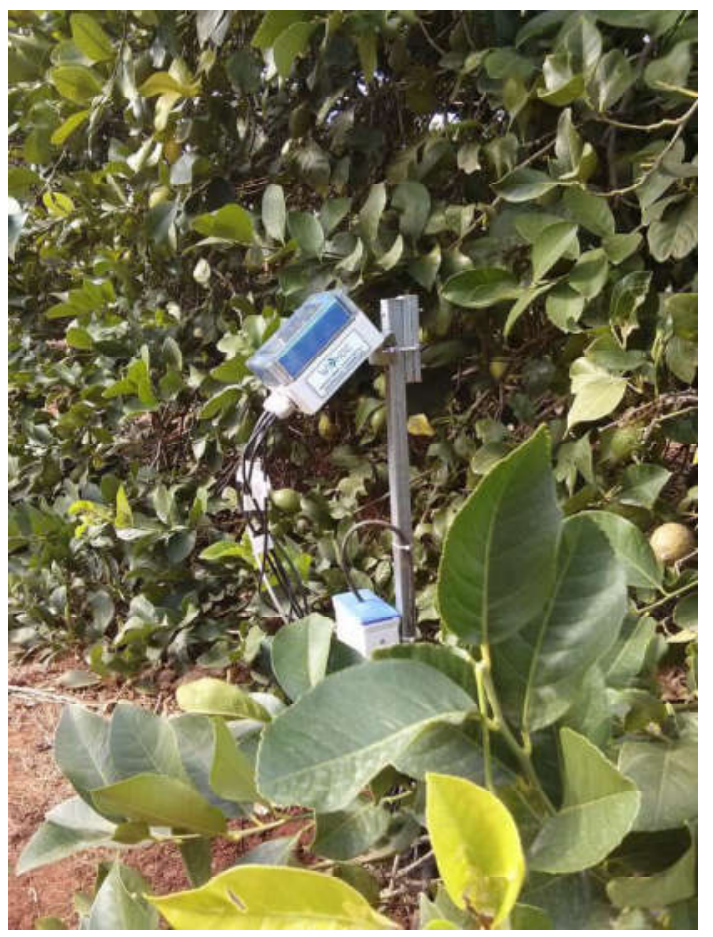

Figure 3: Device installed in a lemon crop field. 
161 autonomy of the device with the equipped solar panel and battery (López Riquelme et al., 2009;

162 Navarro-Hellin et al., 2015). The information is received, processed and stored in a relational 163 database.

\section{2.1.1. Soil Sensors}

165 The soil control variables used to provide SIDSS with relevant information are matric potential

$166\left(\Psi_{\mathrm{m}}\right)$ and volumetric soil water content $\left(\theta_{\mathrm{v}}\right)$, which are common in irrigation management (Jones,

167 2004). By using these variables, the irrigation can be scheduled for maintaining soil moisture

168 conditions equivalent or close to field capacity in order to satisfy the required crop water

169 requirements. Likewise, they can be used to maintain soil water content or soil matric potential

170 under certain reference values proper of regulated deficit irrigation strategies. Both $\Psi_{\mathrm{m}}$ and $\theta_{\mathrm{v}}$ are

171 used to decide the irrigation frequency and to adjust the gross irrigation doses.

172 Soil matric potential was measured with MPS-2 sensors (Decagon devices, Inc., Pullman, WA

17399163 - USA), while volumetric soil water content was measured with both 10-HS (Decagon 174 devices, Inc., Pullman, WA 99163 - USA) and Enviroscan (Sentek Pty. Ltd., Adelaide, Australia) 175 sensors

176 Besides both previous soil sensors, another sensor is used. A pluviometer (Rain-o173-matic 177 small, Pronamic Ltd., Ringkøbing, Denmark) was used under the dripper to provide accurate 178 estimation of the amount of water applied and the irrigation run time. The information provided 179 by this sensor was used to ensure that the farmer is following the instruction of the agronomic 180 reports provided by the expert. Table 2 summarizes the variables measured by the soils sensors. 


\begin{tabular}{|c|c|c|c|c|c|c|c|}
\hline Sensor & Measured data & Variable name & Range & Resolution & $\begin{array}{l}\text { Supply } \\
\text { voltage } \\
\text { range }\end{array}$ & Output & URL \\
\hline $10 \mathrm{HS}$ & soil moisture & VWC1,VWC2,VWC3 & $\begin{array}{c}0 \text { to } 57 \% \\
\text { VWC }\end{array}$ & $0.08 \% \mathrm{VWC}$ & $\begin{array}{l}3-15 \\
\text { VDC }\end{array}$ & $\begin{array}{c}0.3- \\
1.25 \mathrm{~V}\end{array}$ & http://www.decagon.com/ \\
\hline MPS-2 & $\begin{array}{l}\text { soil matric } \\
\text { potential and } \\
\text { temperature }\end{array}$ & $\begin{array}{l}\text { SWP } \\
\text { ST }\end{array}$ & $\begin{array}{c}-10 \text { to }-500 \\
\mathrm{kPa} \\
-40 \circ \text { to }+50 \cong \mathrm{C}\end{array}$ & $\begin{array}{c}0.1 \mathrm{kPa} \\
0.1^{\circ} \mathrm{C}\end{array}$ & $\begin{array}{l}6-15 \\
\text { VDC }\end{array}$ & SDI-12 & http://www.decagon.com/ \\
\hline Enviroscan & soil moisture & VWC1,VWC2,VWC3 & 0 to $65 \%$ VWC & $\begin{array}{c}0.003 \\
\% V W C\end{array}$ & $\begin{array}{l}8-32 \\
\text { VDC }\end{array}$ & $\begin{array}{c}4-20 \\
m A\end{array}$ & http://www.sentek.com.au/ \\
\hline
\end{tabular}

Table 2: Soil sensors technical information

\subsection{Weather Stations}

183 Experiments took place in the Region of Murcia, Spain. In this region, there is a network of 45

184 agro-meteorological stations located in irrigated areas, the Agricultural Information Network

185 System of Murcia (SIAM), funded by the EU and installed to help estimate the reference 186 evapotranspiration $\left(\mathrm{ET}_{0}\right)$ and the irrigation needs of crops after a severe drought between 1979 187 and 1985.

188 The variables measured by the stations are the following:

189 Temperature (T), Relative humidity (RH), Global radiation (GR),Wind speed (WS), Rainfall (RF),

190 Dew point (DP), Vapour pressure deficit (VPD).

191 These variables, measured by the different stations, are publicly available and can be downloaded

192 from the SIAM website (SIAM, 2015). The weather stations are tested and calibrated periodically

193 according to the manufacturer's specifications.

194 The amount of water required to compensate the evapotranspiration loss from the cropped field is

195 defined as crop water requirement. Therefore, knowing the reference crop evapotranspiration is 196 of key importance to estimate the crop's water requirements. Using the FAO Penman-Monteith 
197 formulation (Allen et al., 1998), the daily reference crop evapotranspiration $\left(\mathrm{ET}_{0}\right)$ can be 198 calculated by means of the weather information. The crop evapotranspiration under standard 199 condition $\left(\mathrm{ET}_{\mathrm{c}}\right)$ can be calculated using the single crop coefficient approach shown below:

$200 \quad E T c=K \cdot E T o$

201 where $\mathrm{K}_{\mathrm{c}}$ is the crop coefficient and depends on multiple factors, namely, the crop type, climate, 202 crop evaporation and soil growth stages.

\section{$203 \quad 2.3$ Smart Irrigation Decision Support System}

204 The decision support system is the component in charge of taking the final decision on the 205 amount of water to be irrigated, or equivalently, the number of minutes to irrigate considering 206 constant water flow. This decision is taken automatically on the basis of the information provided 207 by the sensors and the usage of machine learning and pattern recognition techniques. The aim of 208 this component, therefore, is to mimic a human expert in the decision making process of weekly 209 optimising the irrigation, which could assist the farmer.

210 Applying machine learning techniques such as Principal Component Analysis (PCA) or Linear

211 Discriminant Analysis (LDA) allow us to visualize the information to perform an initial 212 exploratory analysis. Figure 4 shows the LDA of the input, array containing the sensorial 213 variables, and output, the estimated irrigation time need, used in the system. The output was 214 divided in classes (18), each one representing the weekly irrigation time by increments of 150 215 minutes, from 0 to 2,700 minutes. From this figure, it can be noticed that discrete classification in 216 classes will be hard to accomplish due to the high number of classes necessary to precisely 217 quantise the irrigation estimation. This is due to the fact that the variable to estimate - either the 
218 amount of water or the watering time- has an intrinsic continuous nature, since the expected

219 output can take any real value between 0 and infinity. Therefore, conventional classifiers aiming 220 categorical outputs - such as LDA (Fisher, 1938), SVM (Belousov et al., 2002), ANN etc. are not 221 optimal for this application. Instead, methodologies based on regression (Wold et al., 222 1984), and/or fuzzy logic (Zadeh et al., 1996) allow us to estimate a more suited continuous 223 variable.

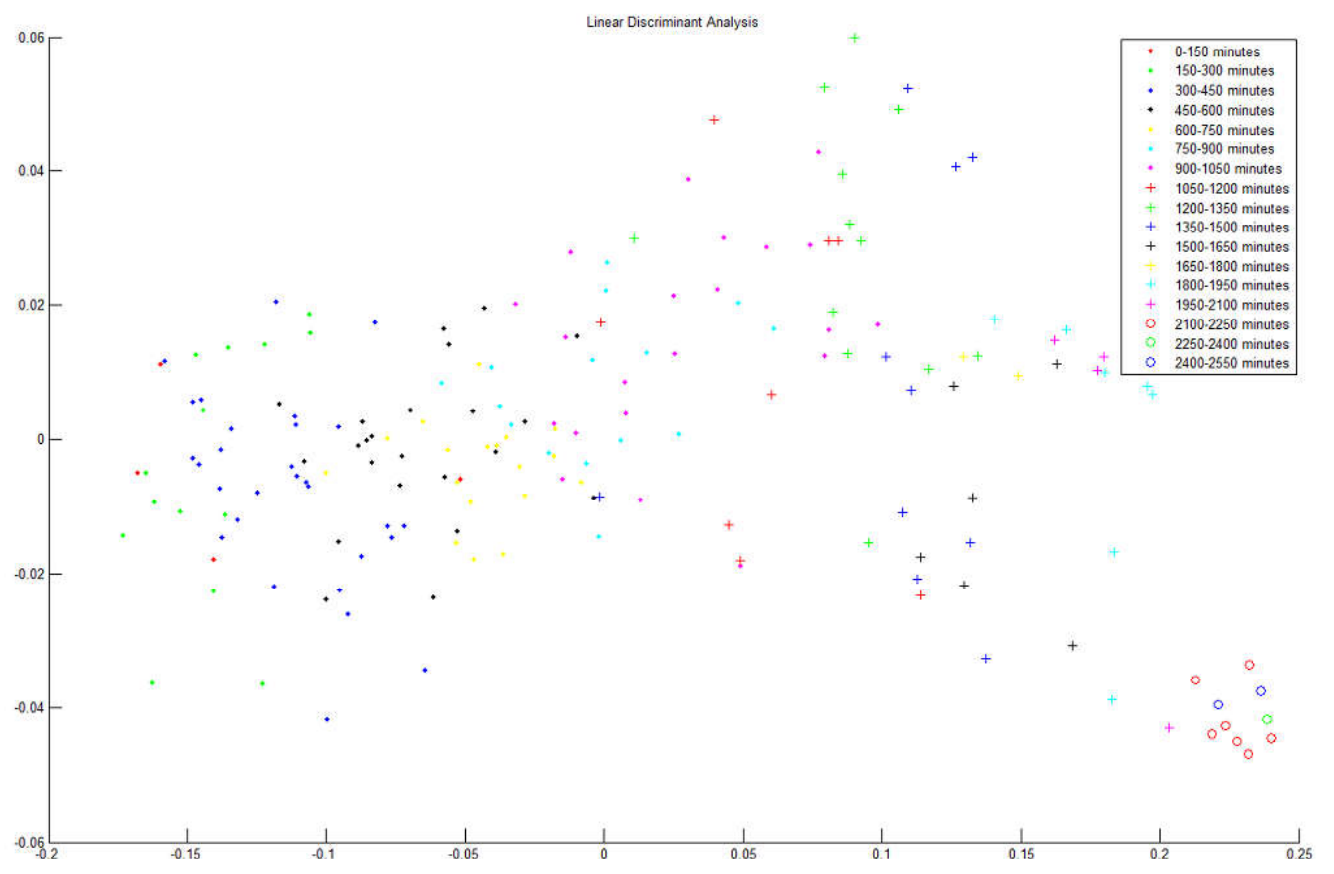

226 In this section, we propose two different techniques, each belonging to one of the previous 227 families, to estimate the weekly required amount of water. As described in the introduction and 228 experimental sections, both modelling techniques require a supervised training set in order to 229 learn the irrigation model. 


\subsubsection{Partial Least Square Regression}

231 Partial Least Square Regression (PLSR) (Wold et al., 2001) is a statistical method that seeks the 232 fundamental relations between predictor and response variables. Predictor variables, $X$, are 233 defined as the observable variables that can be measured and input into the decision system. 234 Response variable $Y$ are the outputs or estimates that must be deducted from the input.

235 The relationship between both variable sets, and linear multivariate regression model, is found by 236 projecting both predicted and observable variables into a new space, where latent variables are 237 estimated to model the covariance structure between the predictor space and the observation 238 space.

239 This PLSR model is developed from a training set $D=\{X, Y\}$ of $S$ samples, which is composed of 240 the predictor matrix $X=\left[x_{1}, \ldots x_{i}, . . x_{S}\right]^{T}$ and the response matrix $Y=\left[y_{1}, . . y_{i}, . . y_{S}\right]^{T} . x_{i}$ is a column 241 vector of $K$ elements, that can contain all the sensor and weather variables measured at a given 242 week $i$ :

$$
x i=\left[V W C 1, V W C 2, V W C 3, M P, S T, E T_{c}, R F, W S, T, R H, G R, D P, V P D\right]^{T}
$$

244 and $y_{i}$ is another column vector of $M$ elements, containing the corresponding variables to be 245 estimated at that week $i$. Since in our application this is only the irrigation time recommended at 246 that week, $y_{i}$ is reduced to a scalar and $M=1$ :

$$
y_{i}=\text { minutes of irrigation }
$$

248 PLSR constructs new predictor latent variables, known as components, which are linear 249 combinations of the original predictor observable variables. These components are created to 250 explain the observed variability in the original predictor variables, while simultaneously 
251 considering the response variable. That is, the estimated latent variables are linear combinations 252 of predictor variables that have higher covariance with $Y$. Using the latent variables leads to a 253 regression models able to fit the response variable with fewer components.

254 The PLSR learning model can be expressed as:

$$
\begin{aligned}
& X=T \cdot P^{T}+E \\
& Y=U \cdot Q^{T}+G
\end{aligned}
$$

257 where $T$ and $U$ are the projections -aka scores- of $X$ and $Y$ into a smaller $L$-dimensional latent 258 space respectively, $P$ and $Q$ are the orthogonal projection matrices -aka loading matrices- and $E$ 259 and $G$ the error residuals. $P$ and $Q$ can be obtained by eigendecomposition of the original 260 matrices.

261 Since the $X$-scores $T$ are meant to be good predictors of $Y$, it can be approximated that:

$$
Y=T \cdot Q^{T}+F
$$

263 Being $F$ a new residual. This reduces the problem to find a set of weights $W$ such that $T=X^{*} W$ 264 predicts $X$ and $Y$ reasonably well. As mentioned, these orthogonal coefficients should maximise 265 the correlation between $X$ and $Y$ while explaining the variance of $X$ :

$$
\max _{w} \operatorname{Corr}^{2}(Y, X) \cdot \operatorname{Var}(X)
$$

$P$ and $Q$ can be solved by applying a Least Square Estimator(LSE) so:

$$
Q^{T}=\left(T^{T} \cdot T\right)^{-1} \cdot T^{T} \cdot Y
$$

$$
P^{T}=\left(T^{T} \cdot T\right)^{-1} \cdot T^{T} \cdot X
$$


270 Finally, by rewriting the previous equation, it can be derived that:

$$
Y=T \cdot Q^{T}+F=X \cdot W \cdot Q^{T}+F=X \cdot B+F
$$

272 Being $B$ the PLSR regression coefficients. Once these coefficients have been learned, responses

$273 \mathrm{y}^{*}$ for new observation $\mathrm{x}^{*}$ can be estimated by applying the learning model:

$$
y^{*}=x^{*} \cdot B+f
$$

assuming an estimation error $f$.

276 We favour the use of PLSR among other regression techniques due to its suitability when the

277 number of predictors is bigger than the number of response variables, the responses are noisy and 278 there is a high probability of having multicollinearity among the predictor variables. The 279 multicollinear phenomenon happens when those variable are highly correlated, due to 280 redundancy between sensors and or between meteorological factors. As it can be noticed, all 281 these factors appear in our irrigation problem.

\subsubsection{Adaptive Neuro Fuzzy Inference Systems}

284 Adaptive Neuro Fuzzy Inference Systems (ANFIS) (Jang, 1993) is a fuzzy inference system for 285 systematically generating fuzzy rules from a given input/output $D$ dataset. This machine learning 286 technique combines advantages from fuzzy logic and artificial neural networks. On the one hand, 287 it allows us to represent an element not only into categories but also into a certain degree of 288 membership functions, which allows mimicking the characteristics of human reasoning and 
289 decision making. On the one hand, it can be trained and so can self-improve in order to adjust the 290 membership functions parameters directly from data (Wang et al., 2006).

291 The ANFIS architecture consists in a five-layer feedforward neural network (Figure 5) whose 292 parameters are updated using a combination of gradient descent and LSE in a two-pass learning 293 algorithm.

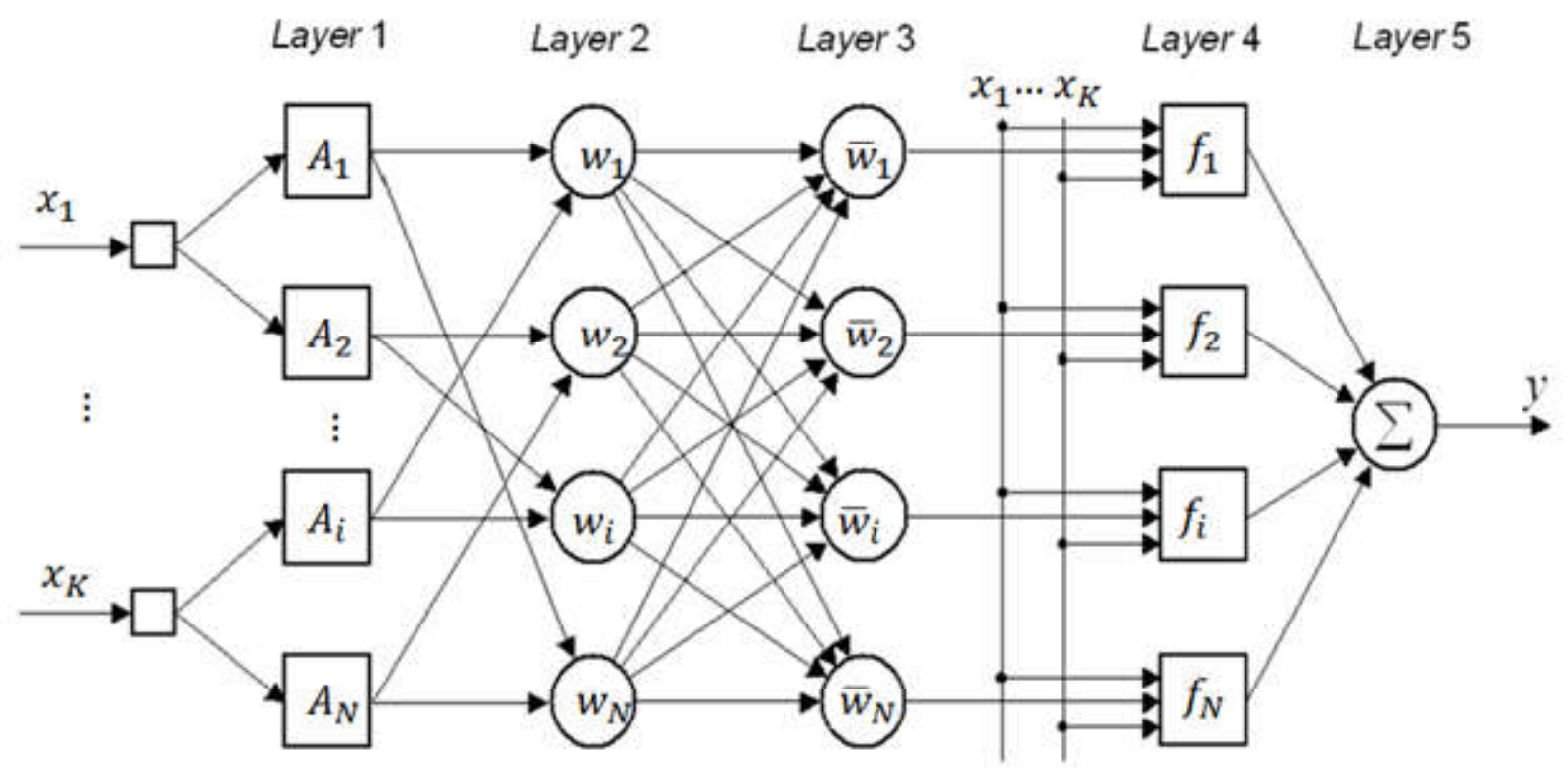

Figure 5: Example of ANFIS architecture for a input $x$ with $K$ variables and a 1-variable output $y$

296 In a first forward pass step, neuron outputs are calculated layer by layer and some internal 297 consequent parameters are identified by the least squares estimator (LSE) to obtain the final 298 single output. The forward pass operation at layer 1 defines the fuzzy membership for each input 299 variable $X$. Assuming a Gaussian distribution function $N\left(c_{n}, \sigma_{n}\right)$, the output of this layer is given 300 by:

$$
O_{1, n}=\mu_{A n}(x)=e^{-\frac{\left(x-c_{n}\right)^{2}}{2 \sigma_{n}^{2}}}
$$


302 Layer 2 is a multiplicative layer, which calculates the firing strength of the rules as a product of 303 the previous membership grades.

$$
O_{2, n}=\mathrm{w}_{n}=\prod_{k_{n}} \mu_{A k_{n}}(x)
$$

305 Layer 3 is a normalising layer, where:

$$
O_{3, n}=\overline{\mathrm{w}}_{n}=\frac{\mathrm{w}_{n}}{\Sigma_{j} \mathrm{w}_{j}}
$$

Layer 4 applies a node function:

$$
O_{4, n}=\overline{\mathrm{w}}_{n} \cdot f_{n}=\overline{\mathrm{w}}_{n} \cdot\left(\sum_{k} p_{k}^{n} x_{k}+r^{n}\right)
$$

where $p^{n}$ and $r^{n}$ are consequent parameters estimated using LSE

310 Finally, layer 5 is the output layer that provides the overall estimation $y$ as a summation of all

311 incoming signals. For the case $M=1$, where only one output variable is estimated:

$$
O_{5,1}=\sum_{n} \overline{\mathrm{w}}_{n} \cdot f_{n}
$$

313 After the forward pass has been completed, an initial estimation is provided by the ANFIS

314 network. Since initial premise parameters $c_{n}, \sigma_{n}$ are initialised randomly, the initial estimation

315 will differ greatly from the desired values $Y$. This error or difference between the desired output $y$

316 and the estimated output $O_{5,1}$ for a given training sample $\left\{x_{i}, y_{i}\right\}$ can be expressed as:

$$
E_{i}=\left(y_{i}-O_{5,1}\right)^{2}
$$

318 To correct this deviation, a second learning step, or backward pass, attempts to minimise the 319 estimated error by modifying the value of the premise parameters until the desired and estimated 320 outputs are similar. This process is performed using backpropagation, where the error is 
321 propagated back over the layers and decomposed into the different nodes using the chain rule.

322 Gradient descend is used as optimisation technique to update the premise parameters while the 323 consequent parameters are kept fixed until the next iteration.

324 This double step learning process is repeated iteratively for every single sample in the training set 325 until the estimated error is smaller than a given threshold, i.e. convergence is achieved, or a 326 maximum number of iterations -epocs- are reached. The ANFIS implementation used in this 327 work is taken from the Fuzzy logic toolbox (Inc, 2016), by Mathworks where the parameter Radii 328 used to train was a scalar of value 0.75 and the average number of epochs used to train was 1500 .

\section{Experimental setup}

330 The system was evaluated in three commercial plantations of lemon trees in the Region of

331 Murcia, located in the semiarid zone of the South-East of Spain where the water is very scarce

332 and drip irrigation is commonly used. The irrigation criteria followed was to maximize the yield.

333 Plantation 1. Fino lemon trees (Citrus limon L. Burm. fil cv. 49) on C. macrophylla Wester, 334 growing in a soil with a low water retention capacity. The soil is characterized by a deep and 335 homogeneous sandy - clay - loam texture. The irrigation water had an electrical conductivity 336 (EC) of $2200 \mu \mathrm{S} \mathrm{cm}^{-1}$. The orchard consist of 11 year old lemon trees with an average height of $3373.5 \mathrm{~m}$. Tree spacing was $7.0 \mathrm{~m}$ x $5.5 \mathrm{~m}$, with an average ground coverage of about 47\%. Two drip 338 irrigation lines $(0.8 \mathrm{~m}$ apart $)$ were used for each tree row. There were 4 emitters $\left(4 \mathrm{~L} \mathrm{~h}^{-1}\right)$ on both 339 sides of each tree. One sensor node was installed in the 5.5 ha orchard, with a soil matric 340 potential sensor (MPS-2, Decagon devices, Inc., Pullman, WA 99163 - USA) at a depth of $30 \mathrm{~cm}$ 
341 and three soil moisture sensors at a depth of 20, 40 and $80 \mathrm{~cm}$ (Enviroscan, Sentek Pty. Ltd.,

342 Adelaide, Australia) located $20 \mathrm{~cm}$ from a representative dripper and $2.25 \mathrm{~m}$ from the trunk.

343 According to the nearest weather station of SIAM, located about $5 \mathrm{~km}$ from the orchard, the

344 climate was typically Mediterranean. Thus, over this period (2014), the annual rainfall for the 345 area was $210 \mathrm{~mm}$ and $\mathrm{ET}_{0}$ was $1395 \mathrm{~mm}$. The average wind speed was $1.66 \mathrm{~m} / \mathrm{s}$, generally light 346 wind and sometimes moderate.

347 Plantation 2 and 3. 40 and 35 year old lemon trees (Citrus limon L. Burm. Fil) cv. Fino and cv.

348 Verna respectively, grafted on sour orange (Citrus aurantium L.), growing in a soil with a 349 medium water retention capacity. The soil is clay sandy loam texture and the irrigation water had 350 an electrical conductivity (EC) of $1600 \mu \mathrm{S} \mathrm{cm}^{-1}$ during all season except in summer which was of $3512285 \mu \mathrm{S} \mathrm{cm}^{-1}$. The tree spacing was $7.0 \mathrm{~m} \times 6.75 \mathrm{~m}$ and $6.75 \mathrm{~m} \times 6.75 \mathrm{~m}$ and the average ground 352 coverage about $57 \%$ and $50 \%$, respectively. One drip irrigation line was used for each tree row.

353 There were 8 and 6 emitters of $4 \mathrm{~L} \mathrm{~h}^{-1}$ per tree, respectively. One sensor node was installed in the 354 Fino orchard ( $\approx 15 \mathrm{ha})$ and another in Verna orchard $(\approx 23 \mathrm{ha})$, each with two soil matric potential 355 sensor (MPS-2, Decagon devices, Inc., Pullman, WA 99163 - USA) at a depth of 25 and $45 \mathrm{~cm}$ 356 and three soil moisture sensors at a depth of 25, 45 and $70 \mathrm{~cm}$ (10HS, Decagon devices, Inc., 357 Pullman, WA 99163) located $20 \mathrm{~cm}$ from a representative dripper and the vertical canopy 358 projection.

359 According to the nearest SIAM's weather station, located about $7 \mathrm{~km}$ from the orchards, the 360 climate was also typically Mediterranean. Over this period (2014), the annual rainfall for the area 
361 was $150 \mathrm{~mm}$ and $\mathrm{ET}_{0}$ was $1250 \mathrm{~mm}$. The average wind speed was $1.4 \mathrm{~m} \mathrm{~s}^{-1}$, i.e. light wind 362 generally.

363 The decision of selecting these three plantations is based on the fact that all of them are mature 364 lemon trees and therefore their water irrigation requirement differences depend mainly of 365 environmental conditions (soil and atmosphere) rather than the plant. Besides, all the plantations 366 use drip emitters of $4 \mathrm{~L} \mathrm{~h}^{-1}$ so estimating the irrigation runtime of the week instead of the water 367 volume will be a correct approach.

368 Drip irrigation provides a fixed volume of water per hour; the pressure is maintained using 369 pressure compensating emitters. The Irrigation frequency is calculated taking into account that 370 only a certain amount of water depletion is allowed before the next replenishment is scheduled.

371 Thus, the run time (gross irrigation dose) is determined to be equivalent to the previous amount 372 of water depletion. The experts only need to calculate the irrigation run time (minutes) and the 373 number of watering times per week or day depending on the time of year or crop development 374 stage. The main goal of the system, also reflected by the expert agronomist in his reports, is to 375 maximize the yield (maximum production per crop surface) with an optimum water management.

376 Since information from the weather stations, soil sensors and crops characteristics has different 377 sampling periods, the first step is pre-process this information. After analysing several methods 378 and time intervals it was decided that the best option was to calculate the week average value for 379 each of the sensors or weather stations variable except for the rainfall where the total amount of 380 rainfall during the week is used instead. The week average fits better than others method like the 381 daily average due to the fact, that the irrigation reports from the expert agronomist are already 382 fixed, limited and done weekly. Besides, adding more input will make the data sparser, making 
383 more difficult to find patterns in the feature space, requiring a higher amount of data to train the 384 system accordingly.

385 The input obtained will be a one dimensional vector $x_{i}$ for each week in which the columns are 386 the different variables or inputs of our system.

387 The target vector will be the water requirements of the crops in the following week $y_{i}$. This 388 information has been extracted from the agronomist expert weekly reports in order to be used as 389 groundtruth for comparison as for supervising the learning process.

390 Three datasets are available, each dataset represent a different plantation. Data was collected 391 from January 2014 until June 2015. Each plantation dataset has 74 weeks of data, which makes a 392 total of 224 weeks of data. To accomplish a proper analysis of the system, we have divided the 393 experiment in two different scenarios. Both scenarios differ from the other on the training and 394 testing split.

395 Two machine learning methods are applied on each scenario, a method based on PLSR and a 396 method based on ANFIS. The performances of both methods in the different scenarios are 397 analysed.

\section{Experimental results and discussion}

\subsection{Scenario 1}

400 In this scenario, we aim to successfully predict the irrigation needs of one or several plantation, 401 based on the information provided by the collection device and learned knowledge from a 402 historical archive of the previous year irrigation reports. This is of obvious usefulness in real life. 
403 We will demonstrate this capability by predicting the irrigation needs of year 2015 for the three

404 plantations based on the information of the year 2014. The training set is therefore composed by 405 all 2014 weeks of data belonging the three plantations, while the test set is composed by all 2015 406 weeks belonging to the three plantations.

407 The information given to the system, or input vector, is a critical part of the design. On the one 408 hand using unnecessary features may make the system perform poorly due to redundant 409 information and noise. On the other hand, using too few features may not provide all the required 410 information. Therefore, among all the available features explained in Table 1, they will not all be 411 necessary. Table 3 shows the features subsets selected for each test. Among all possible sets of 412 features, only combinations with logical sense, according to an expert agronomist were chosen a 413 priori for the different experiments. Performance of the different sets is shown in Figure 6.

\begin{tabular}{|c|c|}
\hline Feature set & Variables \\
\hline $\mathrm{F} 1$ & VWC1,VWC2,VWC3,SWP,ST,ET ${ }_{c}, \mathrm{RF}$ \\
\hline $\mathrm{F} 2$ & VWC1, $\mathrm{ET}_{\mathrm{c}}, \mathrm{RF}$ \\
\hline F3 & SWP,ST, ET ${ }_{c}, \mathrm{RF}$ \\
\hline $\mathrm{F} 4$ & $\mathrm{SWP}, \mathrm{ET}_{\mathrm{c}}, \mathrm{RF}$ \\
\hline F5 & $\mathrm{SWP}, \mathrm{ST}, \mathrm{ET}_{\mathrm{c}}$ \\
\hline F6 & VWC1,SWP,ET \\
\hline F7 & VWC1,SWP, ET ${ }_{c}, \mathrm{RF}$ \\
\hline F8 & VWC1,SWP,ST, ET \\
\hline F9 & VWC1,VWC2,VWC3,SWP,ET \\
\hline F10 & VWC1,SWP \\
\hline F11 & VWC1,VWC2,VWC3,SWP \\
\hline $\mathrm{F} 12$ & $\mathrm{SWP}, \mathrm{ET}_{\mathrm{c}}$ \\
\hline
\end{tabular}



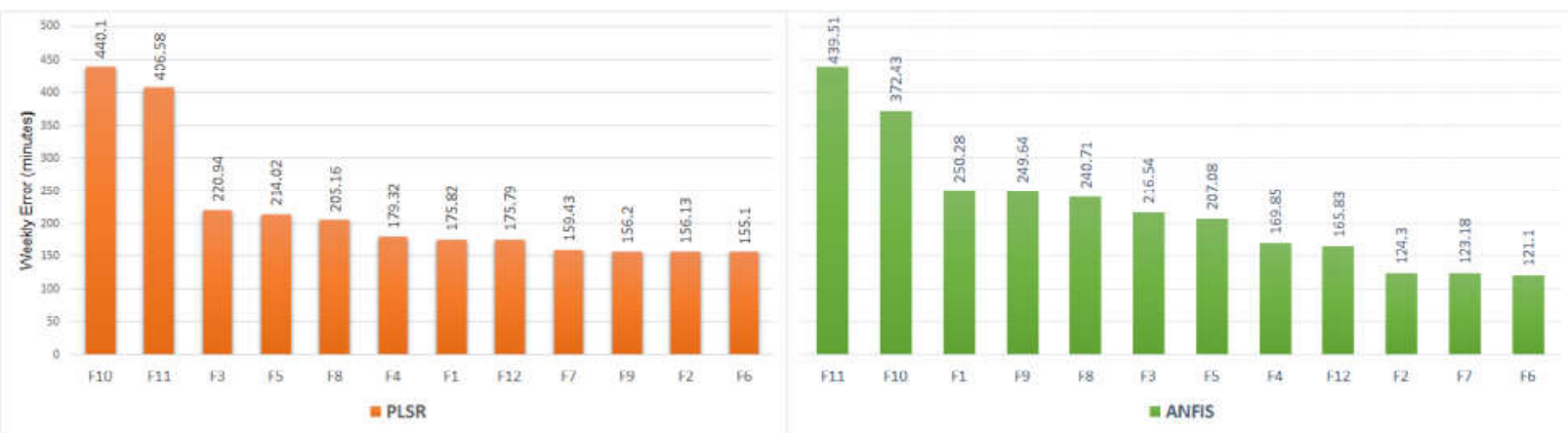

Figure 6: Performance of the different sets of variables for Linear Regression and ANFIS

417 The set that accomplish the best performance for both methods is F6, with and error of 155.1 and

$418121.1 \mathrm{~min}^{\mathrm{week}}{ }^{-1}$ for PLSR and ANFIS respectively. In order to put this error into context, it can

419 be noticed that 2.5 extra hours of irrigation represent around $10 \%$ of the total time in summer 420 months -and up to $20 \%$ in spring and autumn months-, being $10 \%$ error considered as an 421 acceptable error in agriculture (Bos et al., 2004). Therefore, this feature set F6 will be the input 422 vector of the system. It can be noticed that including the rain as input of the system (F7), 423 increases the error. In the Region of Murcia, the rainfall are extremely low (around $210 \mathrm{~mm}$ per 424 year) and usually being concentrated in a few days of the year, being the weekly total rain in most 425 cases 0 . With this information only available for the year 2014, the system didn't have enough 426 information to be trained properly and developed in unpredictable results. However we 427 understand that in other regions the rainfall could be really useful to increase the performance of 428 the system. Besides, considering the water retention capabilities of the soil, part of the rainfalls 429 would be considered in the next irrigation report.

430 Figure 7 shows the water irrigation pattern over time predicted by the PLSR and ANFIS 431 respectively when using feature set 6 . 

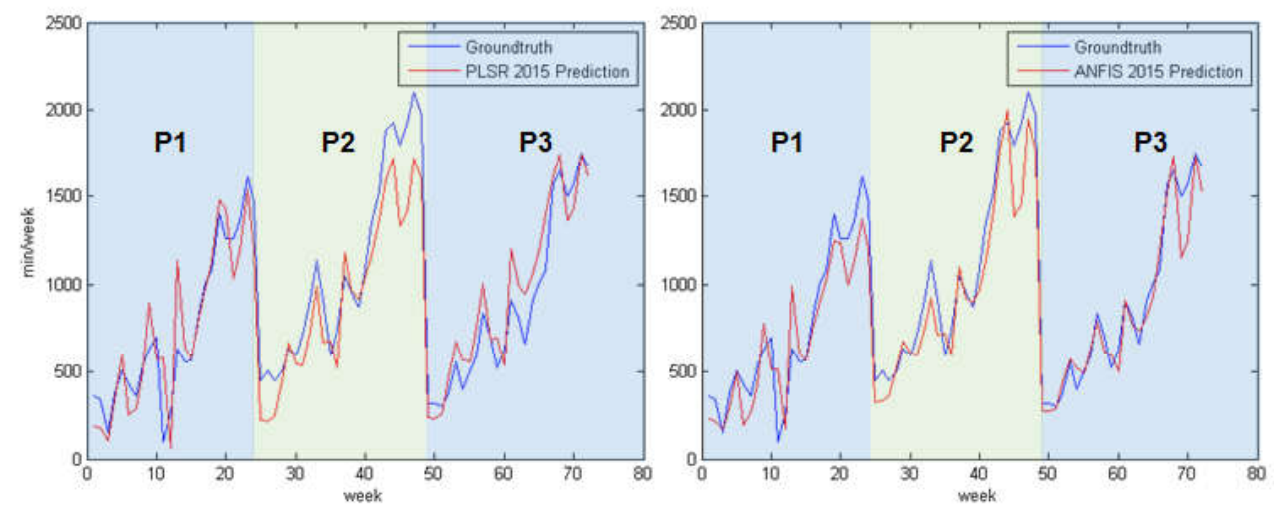

Figure 7: Prediction of the water irrigation pattern using soil and weather information for the different plantations

435 The weekly errors for predicting the irrigation needs during the year 2015 in the three plantations

436 are 155.1 and $121.1 \mathrm{~min}^{-1} \mathrm{wee}^{-1}$ for PLSR and ANFIS respectively. The standard deviation for 437 PLSR is 120.7. In the case of ANFIS, the standard deviation is 105.2. The total amount of time 438 needed to irrigate the crops in the three plantations in 2015 is 65,641 minutes. ANFIS method 439 estimates this value in 60,506 minutes and PLSR estimates 63,240 minutes. As conclusion, 440 ANFIS performance is better than PLSR for each individual week water requirement estimation. 441 However, PLSR estimation also follows the irrigation pattern accurately and estimates the total 442 amount of water required more accurately over time than ANFIS, which seems to be more 443 conservative in the water usage. Looking at the higher peaks of water requirement in the graphs, 444 PLSR may overestimate the water needs while ANFIS is more accurate in general. It is important 445 to note that in agronomy the most important point is not only the amount of water plants need but 446 when they need it (Allen et al., 1998). Following this criterion, the performance of ANFIS is 447 much better than PLSR for this scenario. 
448 Another factor that is important to analyse in this research is the use of soil sensors in addition to

449 weather stations to close the loop. We consider that using this kind of sensors to estimate the 450 water requirements of the crops improves the accuracy of the estimation and helps to deal with 451 local disturbances. Since this is one of our main contributions and differences with other 452 proposed automatic irrigation systems, a detailed analysis of the contribution of these variables is 453 needed to validate our hypotheses and facilitate comparison with previous research systems. 454 Therefore, the input vector was changed, using only weather information to train the system and 455 predict the irrigation time. Table 4 shows the weekly average error for different sets of input 456 vectors.

457 The weather-only input vector that performs best is produced using $\mathrm{ET}_{0}$ exclusively, so this is 458 used in the following analysis as representative of the weather-only prediction systems. Figure 8 459 shows the results of PLSR and ANFIS methods using the $\mathrm{ET}_{\mathrm{c}}$ in comparison to the F6 system.

\begin{tabular}{|c|c|c|c|}
\hline \multirow{2}{*}{ System } & \multirow{2}{*}{ Input Vector } & \multicolumn{2}{|c|}{ Weekly Error (minutes) } \\
\cline { 2 - 4 } & PLSR & ANFIS \\
\hline $\begin{array}{c}\text { Soil + weather } \\
\text { variables (F6) }\end{array}$ & $\mathrm{VWC1,SWP,ET}_{c}$ & 155.1 & 121.1 \\
\hline \multirow{2}{*}{$\begin{array}{c}\text { Only weather } \\
\text { variables }\end{array}$} & $\mathrm{ET}_{\mathrm{c}}$ & 175.3 & 159.6 \\
\cline { 2 - 4 } & $\mathrm{ET}_{c}, \mathrm{RF}$ & 178.4 & 163.6 \\
\cline { 2 - 4 } & $\mathrm{ET}_{c}, \mathrm{RF}, \mathrm{WS}$ & 378.4 & 379.5 \\
\hline
\end{tabular}



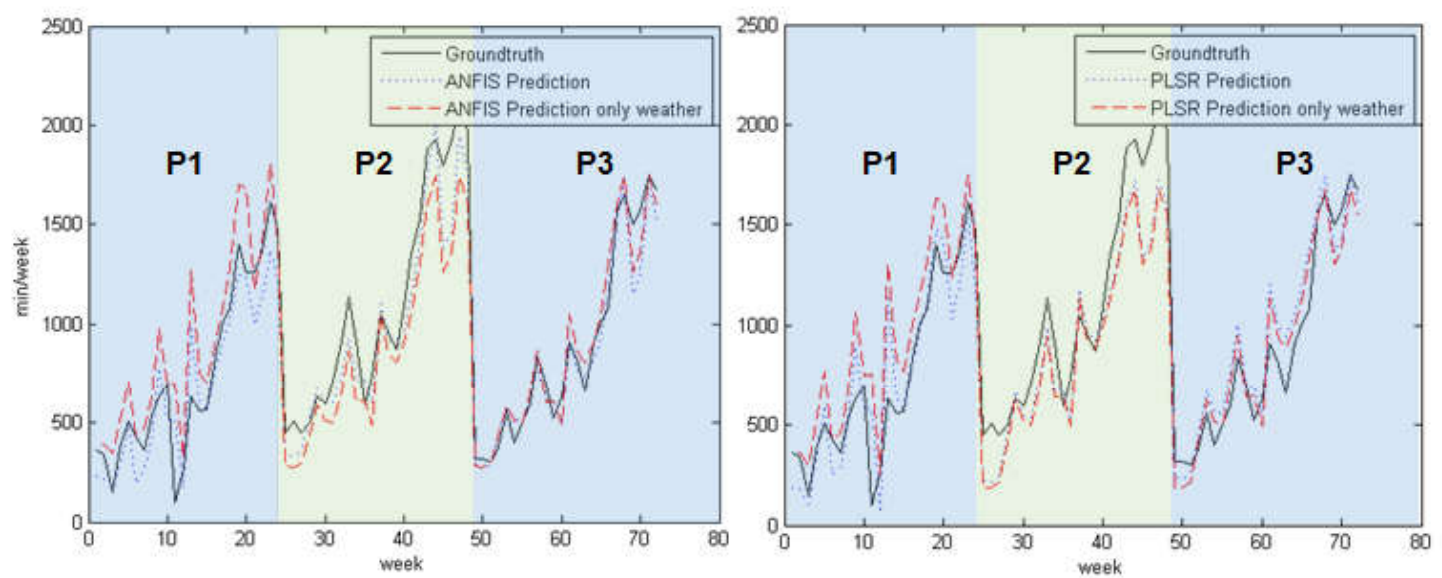

Figure 8: Prediction of the water irrigation pattern using weather information for the different plantations

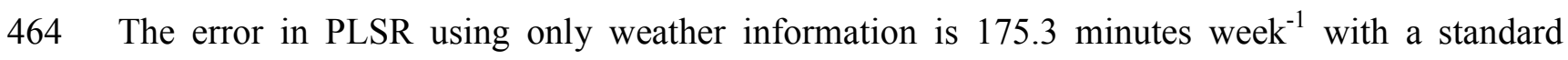

465 deviation of 147.6. In the case of ANFIS, the error is 159.6 minutes week $^{-1}$ with a standard 466 deviation of 146.6 .

467 Although in general the shape of the graph is quite similar to the one using both soil and weather.

468 The use of soil sensors gives a fine adjustment increasing the accuracy of the estimation for both

469 PLSR and ANFIS reasoning engines.

470 It can be concluded that a much better performance in the weekly irrigation estimation (around a $47122 \%$ smaller weekly average error) is achieved when adding soils sensor information to the 472 weather information.

473 Next, a cross-validation strategy is applied to the scenario to validate how the results will 474 generalise to an independent dataset. In cross validation, the complete dataset of the three 475 plantations is divided in training and testing sets. The method used to cross-validate the 
476 information is Leave one out ( $\mathrm{LoO} \mathrm{CV}$ ), a particular case of the Leave-p-out cross-validation 477 (LpO CV). (Kohavi, 1995; Picard and Cook, 1984) that involves using 1 observation as the 478 testing set and the remaining observations as the training set. This process is repeated the number 479 of samples times (n) changing the test sample each time to validate the system with all the 480 samples. Cross validation method was used for both PLSR and ANFIS.

481 Figure 9 shows the results of this LoO Cross-Validation method for PLSR and ANFIS 482 respectively using the set F6 as input vector.

483 The error in PLSR is 277.8 minutes week $^{-1}$ with a standard deviation of 153.2. In the case of 484 ANFIS, the error is 87.6 minutes week ${ }^{-1}$ with a standard deviation of 102.9. The total amount of 485 time needed to irrigate the crops for the 189 weeks in the three plantations is 214,020 minutes. 486 The ANFIS method estimates this value on 213,180 minutes and PLSR estimates 213,960 487 minutes. Table 5 summarizes the result of the experiments.
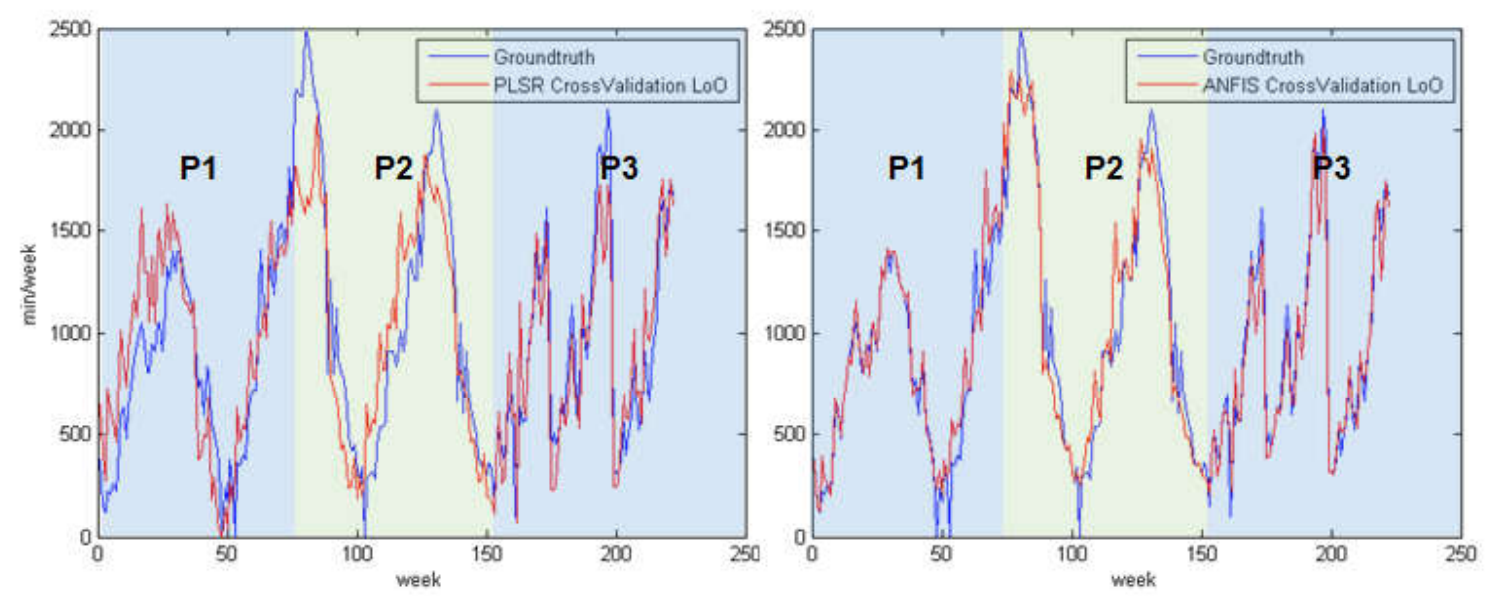

Figure 9: Cross-Validation LoO prediction for Linear Regression and ANFIS. (Plantation 1:Weeks 1-52 and 157180, Plantation 2: Weeks 53-104 and 181-204, Plantation 3: Weeks 105-156 and 205-229)

\begin{tabular}{|l|l|l|}
\hline \multirow{2}{*}{ RESULTS } & \multicolumn{2}{|c|}{ Average weekly error (min.) } \\
\cline { 2 - 3 } & With soil sensors & No soil sensors \\
\hline
\end{tabular}




\begin{tabular}{|l|c|c|cc|}
\hline \multirow{4}{*}{ Scenario 1 } & Predict & PLSR & 155.1 & 175.3 \\
\cline { 3 - 3 } & 2015 & ANFIS & 121.1 & 159.6 \\
\cline { 2 - 3 } & Cross- & PLSR & 277.8 & 295.7 \\
\cline { 2 - 3 } & Validation & ANFIS & 87.6 & 211.9 \\
\hline
\end{tabular}

Table 5: Scenario 1 results summary

492 Similar conclusions are extracted using Cross-Validation. Both PLSR and ANFIS systems are 493 really close to the groundtruth in the total amount of water estimated but it is clear that ANFIS 494 performs much better than PLSR if we consider the weekly error. It is also confirmed that using 495 soil sensors in addition to weather information results in a better performance for both ANFIS and PLSR methods.

The improvement on ANFIS performance during cross validation is explained by the larger amount of training data regarding the "predict 2015" experiment. This behaviour is expected due to the nature of neural networks, which require large amount of data to be trained in comparison

500 with other machine learning techniques and we predict than having a historical archive longer for 501 training could results in a further improvement.

502 Although we are validating our systems with the three plantations described before as case of 503 study, in principle, our methodology has been designed to be independent of the crop, terrain and 504 location of the plantation, aiming to propose a general close-loop automatic irrigation estimator. 505 In practical terms, this means that to apply our system to new plantations, training data in the 506 form of sensor and weather weekly data as well as irrigation reports provided by and expert 507 agronomist for the new plantation will be needed. Since these reports can be expensive and 508 compiling a substantial amount of weekly reports is time consuming and must be planned in 509 advance, it is important to know how big the dataset must be and how the performance may 510 improve with the number of training weeks. 
511 Therefore, as final experiment to obtain an estimation of the required amount of training data for

512 a new crop/plantation, the complete dataset was divided in different percentages of training and

513 testing. Figure 10 shows the weekly error of both PLSR and ANFIS methods with respect to the

514 training dataset percentage.

515 According to the figure, it is noticeable that ANFIS performance is much better than PLSR if

516 there are enough samples to train the system. In cases where the percentage of samples for

517 training is low (less than $25 \%$ of the data, i.e less than 4 months of data for a given field), PLSR

518 overperforms ANFIS. This case is relevant for new plantations without historical data of previous

519 reports. In such situations, the PLSR predictive model may be used in early stages, before

520 switching to ANFIS once enough samples to train the system properly are collected. 


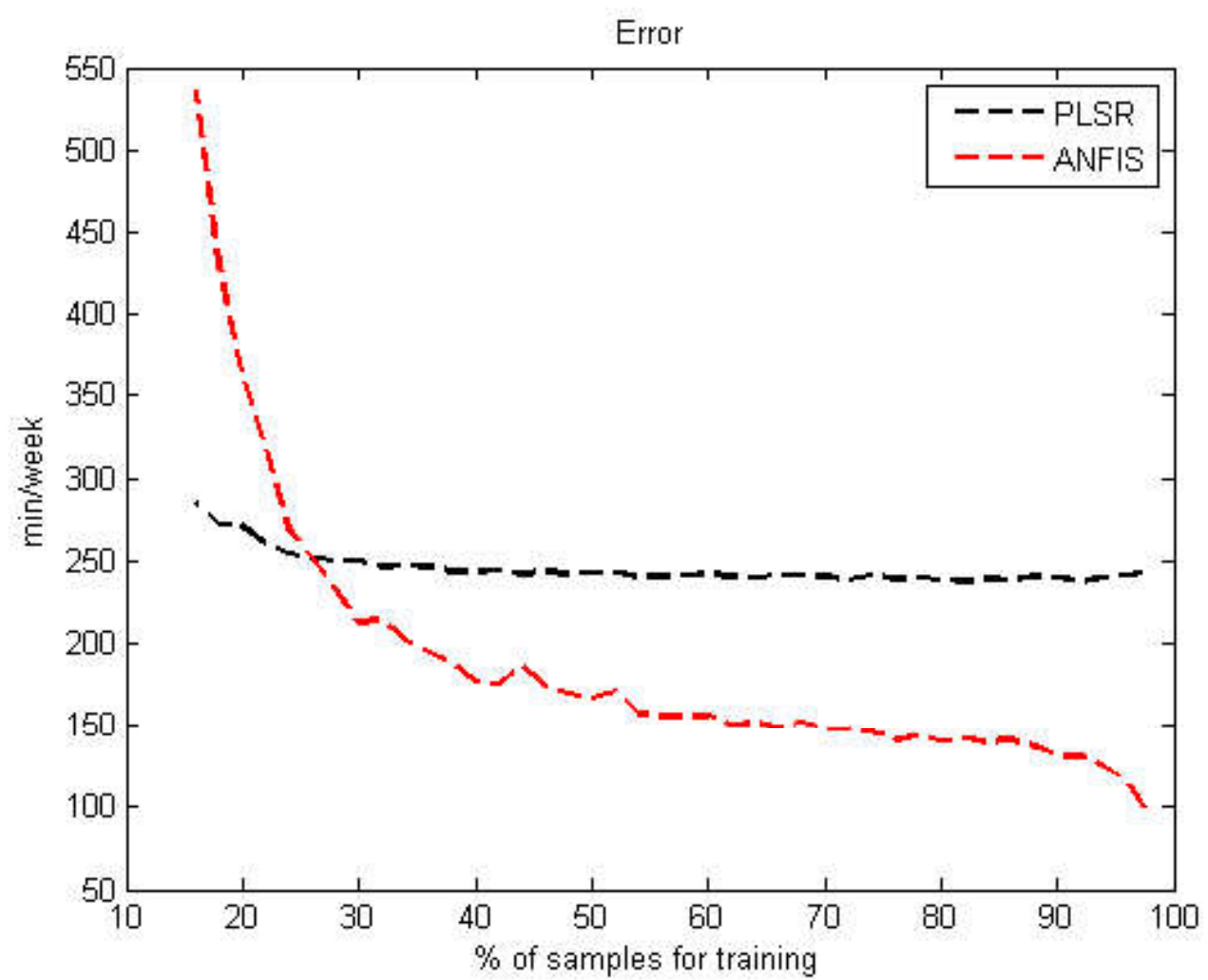

523 Figure 10: Performance comparison for Linear Regression and ANFIS with respect to the \% of samples used to train

\subsection{Scenario 2}

525 The goal is to predict the irrigation of a plantation based on its weather and soil measured 526 variables but using a SIDSS system trained exclusively with other fields. This will be the hardest 527 scenario as it will be necessary to predict the irrigation needs of a field with no previous irrigation 528 reports of that specific plantation. This scenario attempts to show the potential of our 529 methodology to create a universal irrigation estimator of a given crop -in our case, lemon trees530 for any given plantation, independently of the location and/or terrain. A lower performance can 531 be expected in comparison to what could be achieved by retraining the system with information 
532 of the plantation (scenario 1), which is sacrificed for the benefit of not having to generate manual

533 irrigation report for new plantations. Cross validation, specifically leave-one_plantation-out is

534 applied in validation. Thus, 2014 and 2015 data from two of the plantations are used for training,

535 while the remaining plantation data $(2014+2015)$ is used for testing. This is repeated 3 times,

536 leaving a different plantation out of the training set each time, and the results averaged.

537 Table 6 shows the error and standard deviation of this scenario for PLSR and ANFIS using

538 different features vector used to compare the performance.

\begin{tabular}{|c|c|c|c|c|c|c|c|c|c|}
\hline \multirow[b]{2}{*}{ Method } & \multirow[b]{2}{*}{ Features vector } & \multicolumn{2}{|c|}{ Test Plantation 1} & \multicolumn{2}{|c|}{ Test Plantation 2} & \multicolumn{2}{|c|}{ Test Plantation 3} & \multicolumn{2}{|c|}{ Total } \\
\hline & & $\begin{array}{c}\text { Weekly } \\
\text { Error (min) }\end{array}$ & Std & $\begin{array}{c}\text { Weekly } \\
\text { Error } \\
\text { (min) }\end{array}$ & Std & $\begin{array}{c}\text { Weekly } \\
\text { Error } \\
\text { (min) }\end{array}$ & Std & $\begin{array}{c}\text { Average } \\
\text { Weekly } \\
\text { Error } \\
\text { (min) }\end{array}$ & $\begin{array}{c}\text { Average } \\
\text { Std }\end{array}$ \\
\hline PLSR & $V W C 1+S W P+E T C$ & 364.1 & 205.6 & 179.4 & 141.2 & 227.5 & 185.8 & 257.0 & 177.5 \\
\hline ANFIS & $V W C 1+S W P+E T C$ & 373.2 & 300.7 & 175.4 & 129.8 & 421.4 & 495.5 & 323.3 & 308.6 \\
\hline PLSR & SWP+ETC & 182.2 & 133.3 & 176.2 & 120.9 & 224.9 & 172.38 & 194.4 & 142.2 \\
\hline ANFIS & $S W P+E T C$ & 200.8 & 140.1 & 156.5 & 126.9 & 234.8 & 192.6 & 197.4 & 153.2 \\
\hline
\end{tabular}

Table 6: Scenario 2 results summary

540 The best feature vector F6 used in scenario 1 is used as input. In this case PLSR outperforms

541 ANFIS with an average error of 257.0 minutes in comparison with 323.3 minutes for ANFIS.

542 However, we noticed that, in this scenario, removing the VWC1 sensor results in a better

543 performance for both methods as a universal estimator. This is explained because the VWC

544 sensor is very dependent on the soil where it is installed and, as both algorithms were trained with

545 a sensor installed in a different plantation than the one that is predicting, the provided information

546 introduces noise and does not help the system to estimate properly the water need. This does not 
547 happen, however, with the SWP sensor, which quantifies the tendency of water to move from one 548 area to another in the soil and it is less dependent on the soil installed. Removing the VWC 549 sensor results in a better performance of the system obtaining an average weekly error of 194.4 550 minutes with PLSR and 197.4 minutes with ANFIS. This result proves that there is certain 551 potential to develop a universal estimator using our system for a given crop, although this means 552 an increase of the average error. This error could be reduced if more than 2 plantations of the 553 same crop were available for training. Both PLSR and ANFIS performs similarly, being PLSR 554 slightly better.

\section{Conclusions}

556 This paper describes the design and development of an automatic decision support system to 557 manage irrigation in agriculture. The main characteristic of system is the use of continuous soil 558 measurements to complement climatic parameters to precisely predict the irrigation needs the 559 crops, in contrast with previous works that are based only on weather variables or doesn't specify 560 the quantity of water required by the crops. The use of real-time information from the soil 561 parameters in a closed loop control scheme allows adapting the decision support system to local 562 perturbations, avoiding the accumulative effect due to errors in consecutive weekly estimation, 563 and/or detecting if the irrigation calculated for the SIDSS has been performed by the farmer. The 564 analysis of the performance of the system is accomplished comparing the decisions taken by a 565 human expert and the decision support component. Two machine learning techniques, PLSR and 566 ANFIS, have been proposed as the basis of our reasoning engine and analysed in order to obtain 567 the best performance. 
568 The experiments have taken place in three commercial plantations of citrus trees located in the 569 South-East of Spain. A first experimental scenario shows a comparison of the system's 570 performance using soil sensors in addition to the weather information for predicting year 2015 571 using 2014 information to train the system. The usage of soil sensor in the three plantations 572 accomplished a $22 \%$ less of weekly error in comparison to the performance of using only weather 573 information.

574 A second scenario shows the potential of our system as universal estimator for a given crop, i.e 575 the use case of installing the system in a new plantation, not having previous information of it. 576 For this application, VWC sensors should be removed due to their high dependence with the soil 577 type. Although, as expected, the estimation error increases in this scenario, it does not require 578 historical data from agronomical reports to be retrained, which implies a significant advantage, in 579 particular for new plantations in early stages. If more training data from a bigger variety of field 580 were available, a better performance in this scenario could be expected. Another possible 581 improvement for this scenario will be the addition of a VWC to get a better performance than 582 using only the matric potential sensors. However, in order to use the VWC sensor in this 583 scenario, a precise study of the soil textures of the plantation will be required to extrapolate the 584 VWC sensor information to similar soil textures where the DSS was trained.

585 For future research, we aim to extend and evaluate the system in plantations different than citrus 586 and analyse the performance under several conditions and regions. Thus, adding the weather 587 forecast as input of the SIDSS could help to improve the next week irrigation schedule and 588 consider the predicted rainfall in our estimation. Similarly, past rainfall information, that did not 589 prove beneficial in our system due to the region of Murcia characteristics, may become a good 
590 factor to improve the accuracy of the system in regions with a more regular and predictable

591 raining pattern. We also aim to capture a bigger dataset that will allow us to generate more 592 general models towards a universal irrigation estimator of a given crop. This dataset will also 593 explore the use of multiple sensors per plantation in order to address inhomogeneous ground 594 conditions in the different plantation as well as provide more input information to the system for 595 a better reasoning.

\section{Aknowledgments}

597 The development of this work was supported by the Spanish Ministry of Science and Innovation 598 through the projects MICINN, AGL2010-19201-C04-04 and MINECO, AGL2013-49047-C2-1599 R. We would like to thank Widhoc Smart Solutions S.L. and Queen's Belfast University for 600 letting us use their facilities and equipment to carry out the tests.

\section{References}

603 Abrisqueta, I., Conejero, W., Valdés-Vela, M., Vera, J., Ortuño, M.F., Ruiz-Sánchez, M.C., 2015.

604 Stem water potential estimation of drip-irrigated early-maturing peach trees under Mediterranean 605 conditions. Computers and Electronics in Agriculture 114, 7-13. 606 doi:10.1016/j.compag.2015.03.004

607 Adeloye, A.J., Rustum, R., Kariyama, I.D., 2012. Neural computing modeling of the reference 608 crop evapotranspiration. Environ. Model. Softw. 29, 61-73. doi:10.1016/j.envsoft.2011.10.012

609 Allen, R.G., Pereira, L.S., Raes, D., Smith, M., 1998. Crop Evapotranspiration: Guidelines for 
610 Computing Crop Water Requirements. FAO Irrigation and Drainage Paper No. 56.

611 Belousov, A.I., Verzakov, S.A., von Frese, J., 2002. A flexible classification approach with 612 optimal generalisation performance: support vector machines. Chemom. Intell. Lab. Syst. 64, 15613 25. doi:10.1016/S0169-7439(02)00046-1

614 Bos, M.G., Burton, M.A., Molden, D.J. (Eds.), 2004. Irrigation and drainage performance 615 assessment: practical guidelines. CABI, Wallingford.

616 Campos, I., Balbontín, C., González-Piqueras, J., González-Dugo, M.P., Neale, C.M.U., Calera, 617 A., 2016. Combining a water balance model with evapotranspiration measurements to estimate 618 total available soil water in irrigated and rainfed vineyards. Agricultural Water Management 165, $619 \quad 141$ - 152. doi:http://dx.doi.org/10.1016/j.agwat.2015.11.018

620 Cardenas-Lailhacar, B., Dukes, M.D., 2010. Precision of soil moisture sensor irrigation 621 controllers under field conditions. Agric. Water Manag. 97, 666-672. 622 doi:10.1016/j.agwat.2009.12.009

623 Dutta, R., Morshed, A., Aryal, J., D'Este, C., Das, A., 2014. Development of an intelligent 624 environmental knowledge system for sustainable agricultural decision support. Environ. Model. 625 Softw. 52, 264-272. doi:10.1016/j.envsoft.2013.10.004

626 Fisher, R.A., 1938. The Statistical Utilization of Multiple Measurements. Ann. Eugen. 8, 376627 386. doi:10.1111/j.1469-1809.1938.tb02189.x

628 Giusti, E., Marsili-Libelli, S., 2015. A Fuzzy Decision Support System for irrigation and water 629 conservation in agriculture. Environ. Model. Softw. 63, 73-86. 630 doi:10.1016/j.envsoft.2014.09.020 
631 Guariso, G., Rinaldi, S., Soncini-Sessa, R., 1985. Decision support systems for water 632 management: The Lake Como case study. Eur. J. Oper. Res. 21, 295-306. doi:10.1016/0377$633 \quad 2217(85) 90150-X$

634 IDAE, 2005. Ahorro y Eficiencia Energética en Agricultura de Regadío. Madrid.

635 Jang, J.-S.R., 1993. ANFIS: adaptive-network-based fuzzy inference system. IEEE Trans. Syst. 636 Man Cybern. 23, 665-685. doi:10.1109/21.256541

637 Jensen, M.E., Robb, D.C.N., Franzoy, C.E., 1970. Scheduling Irrigations Using Climate-Crop638 Soil Data. J. Irrig. Drain. Div. 96, 25-38.

639 Jones, H.G., 2004. Irrigation scheduling: advantages and pitfalls of plant-based methods. J. Exp. 640 Bot. 55, 2427-2436. doi:10.1093/jxb/erh213

641 King, B.A., Shellie, K.C., 2016. Evaluation of neural network modeling to predict non-water642 stressed leaf temperature in wine grape for calculation of crop water stress index. Agricultural 643 Water Management 167, 38 - 52. doi:http://dx.doi.org/10.1016/j.agwat.2015.12.009

644 Kohavi, R., 1995. A Study of Cross-validation and Bootstrap for Accuracy Estimation and Model 645 Selection, in: Proceedings of the 14th International Joint Conference on Artificial Intelligence 646 Volume 2, IJCAI'95. Morgan Kaufmann Publishers Inc., San Francisco, CA, USA, pp. 1137$647 \quad 1143$.

648 Kramer, P.J., Boyer, J.S., 1995. Water relations of plants and soils. Academic Press, Inc. 
649 López Riquelme, J.A., Soto, F., Suardíaz, J., Sánchez, P., Iborra, A., Vera, J.A., 2009. Wireless 650 Sensor Networks for precision horticulture in Southern Spain. Computers and Electronics in 651 Agriculture 68, 25-35. doi:10.1016/j.compag.2009.04.006

652 Maton, L., Leenhardt, D., Goulard, M., Bergez, J.-E., 2005. Assessing the irrigation strategies 653 over a wide geographical area from structural data about farming systems. Agric. Syst. 86, 293654 311. doi:10.1016/j.agsy.2004.09.010

655 Naor, A., Hupert, H., Greenblat, Y., Peres, M., Kaufman, A., Klein, I., 2001. The Response of 656 Nectarine Fruit Size and Midday Stem Water Potential to Irrigation Level in Stage III and Crop 657 Load. J. Am. Soc. Hortic. Sci. 126, 140-143.

658 Navarro-Hellín, H., Torres-Sánchez, R., Soto-Valles, F., Albaladejo-Pérez, C., López-Riquelme, 659 J.A., Domingo-Miguel, R., 2015. A wireless sensors architecture for efficient irrigation water 660 management. Agric. Water Manag., New proposals in the automation and remote control of water 661 management in agriculture: agromotic systems 151, 64-74. doi:10.1016/j.agwat.2014.10.022

662 Picard, R.R., Cook, R.D., 1984. Cross-Validation of Regression Models. Journal of the American 663 Statistical Association 79, 575-583. doi:10.2307/2288403

664 Puerto, P., Domingo, R., Torres, R., Pérez-Pastor, A., García-Riquelme, M., 2013. Remote 665 management of deficit irrigation in almond trees based on maximum daily trunk shrinkage. Water 666 relations and yield. Agric. Water Manag. 126, 33-45. doi:10.1016/j.agwat.2013.04.013

667 SIAM, 2015. Red del Sistema de Información Agrario de Murcia. URL siam.imida.es

668 Smith, M., 2000. The application of climatic data for planning and management of sustainable 669 rainfed and irrigated crop production. Agric. For. Meteorol. 103, 99-108. doi:10.1016/S0168- 
671 Soulis, K.X., Elmaloglou, S., Dercas, N., 2015. Investigating the effects of soil moisture sensors 672 positioning and accuracy on soil moisture based drip irrigation scheduling systems. Agric. Water 673 Manag. 148, 258-268. doi:10.1016/j.agwat.2014.10.015

674 Sreekanth, M.S., Rajesh, R., Satheeshku, J., 2015. Extreme Learning Machine for the 675 Classification of Rainfall and Thunderstorm. Journal of Applied Sciences 15, 153-156. 676 doi:10.3923/jas.2015.153.156

677 Valdés-Vela, M., Abrisqueta, I., Conejero, W., Vera, J., Ruiz-Sánchez, M.C., 2015. Soft 678 computing applied to stem water potential estimation: A fuzzy rule based approach. Comput. 679 Electron. Agric. 115, 150-160. doi:10.1016/j.compag.2015.05.019

680 Wang, Z., Palade, V., Xu, Y., 2006. Neuro-Fuzzy Ensemble Approach for Microarray Cancer 681 Gene Expression Data Analysis, in: 2006 International Symposium on Evolving Fuzzy Systems. 682 Presented at the 2006 International Symposium on Evolving Fuzzy Systems, pp. 241-246. 683 doi:10.1109/ISEFS.2006.251144

684 Wold, S., Ruhe, A., Wold, H., Dunn, I., W., 1984. The Collinearity Problem in Linear 685 Regression. The Partial Least Squares (PLS) Approach to Generalized Inverses. SIAM J. Sci. 686 Stat. Comput. 5, 735-743. doi:10.1137/0905052

687 Wold, S., Sjöström, M., Eriksson, L., 2001. PLS-regression: a basic tool of chemometrics. 688 Chemom. Intell. Lab. Syst., PLS Methods 58, 109-130. doi:10.1016/S0169-7439(01)00155-1

689 Zadeh, L.A., Klir, G.J., Yuan, B., 1996. Fuzzy Sets, Fuzzy Logic, and Fuzzy Systems: Selected 690 Papers by Lotfi A Zadeh, Advances in Fuzzy Systems - Applications and Theory. WORLD 


\section{SCIENTIFIC.}

692 Zwart, S.J., Bastiaanssen, W.G.M., 2004. Review of measured crop water productivity values for 693 irrigated wheat, rice, cotton and maize. Agric. Water Manag. 69, 115-133. 694 doi:10.1016/j.agwat.2004.04.007 